\title{
EARLY ONSET CATARACT IN AN INFANT WITH ACTIVATING CALCIUM SENSING RECEPTOR (CaSR) MUTATION
} Royal Surrey County Hospital WHS

\author{
Priya Ramaswamy ${ }^{1}$, Michael Ryalls ${ }^{2}$, Jeremy Allgrove ${ }^{1}$ \\ 1.Barts Health NHS Trust, London, UK \\ 2.Royal Surrey County Hospital, Guildford, UK
}

\section{INTRODUCTION}

CaSR is a G-protein coupled receptor which senses extracellular levels of calcium ion. Activating CaSR gene variants result in an increased calcium sensitivity in parathyroid and renal cells, which reduces the parathyroid set point and reduces renal calcium re-absorption despite prevailing hypocalcaemia. The clinical presentation varies from mild paraesthesia and muscle cramps to nephrocalcinosis, nephrolithiasis, basal ganglia calcifications and seizures while some remain asymptomatic.

\section{CASE STUDY}

We present a case of a two month old boy with an activating mutation of CaSR who presented with recurrent hypocalcaemic seizures, which settled with parathyroid hormone (PTH) infusion. However, he developed cataract at six weeks of age.

\section{BACKGROUND}

- Male infant, spontaneous vaginal delivery at term

- Second born of healthy non-consanguineous parents

- Good condition at birth, Birth Weight $4.19 \mathrm{~kg}$

- Newborn examination and eye examination normal

\section{CLINICAL PRESENTATION}

- Admitted at seven days of life with focal seizures

- Hypocalcaemia with inappropriately low PTH levels

- Treated with intravenous calcium and magnesium

- Discharged on oral calcium, magnesium, alfacalcidol

Re-admitted at five weeks; recurrent focal seizures

Hypocalcaemia persistent despite treatment

Stopped fixing and following over the last week

Nystagmus present and red reflexes absent

Ophthalmology confirmed dense bilateral cataract

\section{CLINICAL MANAGEMENT}

- Commenced on subcutaneous PTH infusion

- Weaned off intravenous calcium infusion

- Alfacalcidol stopped and Colecalciferol commenced

- Seizures settled after resolution of hypocalcaemia

- Thiazides started to reduce renal calcium excretion

- Urine calcium creatinine ratio was monitored

- Operated for cataract at nine weeks of life

\section{INVESTIGATIONS}

- Calcium $1.5(2.0-2.7) \mathrm{mmol} / \mathrm{l}$

- Magnesium $0.6(0.7$ - 1.0) $\mathrm{mmol} / \mathrm{l}$

- Phosphate 3.7(1.3 - 2.6) $\mathrm{mmol} / \mathrm{l}$

- PTH <0.3 (1.5- $\quad<.6) \mathrm{pmol} / \mathrm{l}$

Activating mutation in the CaSR gene confirmed Heterozygous for c.2486A>G, p.(Tyr829Cys)

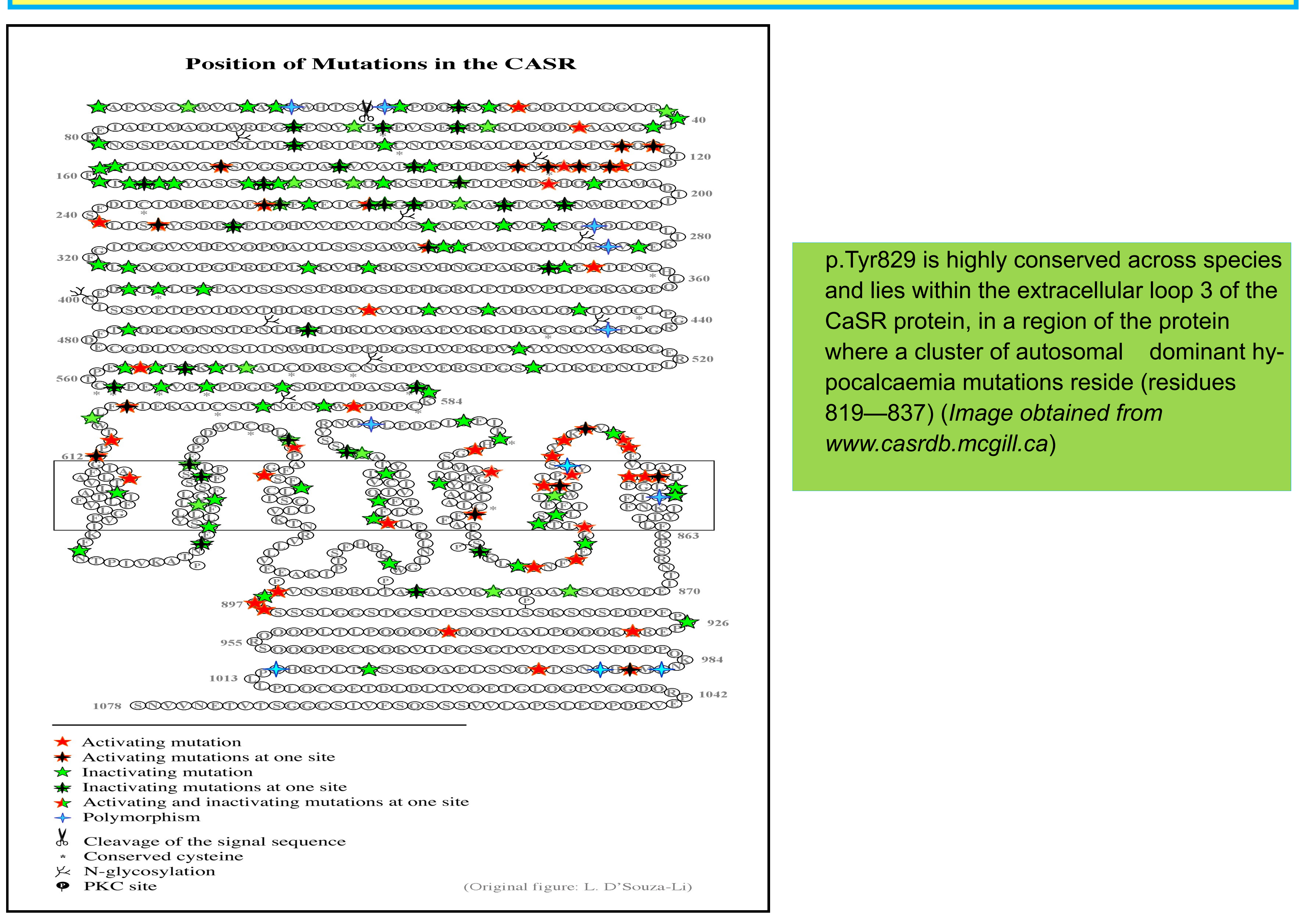

\section{CONCLUSION}

Hypoparathyroidism is known to be associated with cataract formation

- As far as we are aware, this is the first reported case of cataract in infants with activating CaSR mutation, although it has been previously identified in a mouse model

- We therefore suggest that evaluation for cataract is required in this subgroup of patients 